\title{
A Method for Quantifying the Synergistic Inhibitory Effect of Corrosion Inhibitors When Used in Combination: A 'Chromate Generating Coating'
}

\author{
N. Wint, ${ }^{*, z}$ P. Ansell, J. Edy, G. Williams, and H. N. McMurray* \\ Materials Research Centre, College of Engineering, Swansea University, Bay Campus, Crymlyn Burrow, Swansea SA1 \\ $8 E N$, United Kingdom
}

\begin{abstract}
Corrosion inhibitive pigments, based on the cations $\mathrm{Ce}^{4+}$ and $\mathrm{Cr}^{3+}$ exchanged into smart release resins, are dispersed in a polyvinyl butyral (PVB) model coating and applied to a hot dip galvanised steel (HDG) substrate. An investigation is made into the influence of different pigment volume fractions $\left(\varnothing_{\text {pig }}\right)$ of $\mathrm{Ce}(\mathrm{IV})$ and $\mathrm{Cr}(\mathrm{III})$ based inhibitors, used both in isolation and combination, on the kinetics and mechanism of corrosion driven cathodic coating delamination. The rate of coating delamination is obtained using scanning Kelvin probe (SKP) potentiometry and time lapse photography, and the efficiency with which each inhibitor combination is able to resist cathodic coating delamination is calculated. Isobolograms, commonly utilized within the field of drug interaction, are presented as an effective method for characterising corrosion inhibitor interactions. In some cases, the sum of the efficiencies calculated for $\mathrm{Ce}(\mathrm{IV})$ and $\mathrm{Cr}(\mathrm{III})$ based pigments is shown to be greater than the sum of their individual efficiencies. It is proposed that $\mathrm{Ce}^{4+}$, released upon electrolyte exposure, is able to oxidize the $\mathrm{Cr}^{3+}$ species resulting in the formation of transient $\mathrm{CrO}_{4}{ }^{-2}$.

(C) The Author(s) 2019. Published by ECS. This is an open access article distributed under the terms of the Creative Commons Attribution 4.0 License (CC BY, http://creativecommons.org/licenses/by/4.0/), which permits unrestricted reuse of the work in any medium, provided the original work is properly cited. [DOI: 10.1149/2.1021914jes]

(cc) BY
\end{abstract}

Manuscript submitted June 28, 2019; revised manuscript received September 26, 2019. Published November 18, 2019.

Technologically important zinc based coatings, used heavily throughout the construction and automotive industries, are commonly over-coated with organic layers. Such coating systems consist of several components including corrosion inhibitor pigments dispersed within a primer layer. ${ }^{1}$ Historically, some of the most effective of the inhibitory pigments have been based on chromium in the hexavalent oxidation state $(\mathrm{Cr}(\mathrm{VI}))$ and these are predominantly used in the form of chromate or dichromate salts $\left(\mathrm{CrO}_{4}{ }^{2-}\right.$ or $\left.\mathrm{Cr}_{2} \mathrm{O}_{7}\right)$. However, these chemistries are currently being phased out of use under Registration, Evaluation, Authorisation and Restriction of Chemicals $(\mathrm{REACH})$ regulations, ${ }^{2,3}$ and their replacement with non-toxic, noncarcinogenic, environmentally friendly 'green' substitutes is therefore a topic of much research interest. ${ }^{4-12}$ Despite ongoing effort, an alternative which offers corrosion inhibition greater than, or equal to, that afforded by chromate has not yet been identified. An increasing amount of research is focused on the ability of two or more inhibitors to provide corrosion protection when used in conjunction with one another. However, the synergistic effect of such inhibitor mixtures is difficult to quantify. Our paper therefore aims to provide a timely and useful method by which to quantitatively characterize the synergistic effect of two corrosion inhibitors when used together.

One multi-inhibitor approach involves the formulation of the organic coating without inclusion of $\mathrm{Cr}(\mathrm{VI})$, but in such a way that $\mathrm{Cr}(\mathrm{VI})$ can be evolved transiently when corrosive electrolyte ingresses at coating defects. ${ }^{6-8}$ The proposed novel coating incorporates a source of benign trivalent chromium $(\mathrm{Cr}(\mathrm{III}))$ species, together with a separate oxidizing agent. In one implementation an ion exchange pigment (hydrotalcite) contains the water soluble permanganate anion $\left(\mathrm{MnO}_{4}^{-}\right)$as the oxidizing agent. The use of an ion exchange delivery system (such as hydrotalcite) ensures that the $\mathrm{MnO}_{4}^{-}$becomes released only upon exposure to an electrolyte which contains anions with which it can exchange. ${ }^{6-8}$ The release of $\mathrm{MnO}_{4}^{-}$results in the oxidation of $\mathrm{Cr}$ (III) and 'transient' production of a water soluble $\mathrm{CrO}_{4}{ }^{2-}$, which is then able to travel through the electrolyte to sites of corrosive attack. ${ }^{6-9}$ When corrosion and electrolyte ingress ceases, so does the production of chromate. The chromate ions which have been released will slowly become reduced back down. On this basis, the proposed novel coating is able to provide the corrosion inhibition associated with chromates, whilst the environmental and health risks associated with coating formulation and recycling are mitigated. The mechanism by which the "chromate generating coating" described here is proposed to work

\footnotetext{
*Electrochemical Society Member
}

${ }^{\mathrm{z} E-m a i l: ~ n . w i n t @ s w a n s e a . a c . u k ~}$ means that two inhibitor components, the first based on $\mathrm{Cr}(\mathrm{III})$ and the second on an oxidizing agent, must be used in combination in order to provide adequate corrosion inhibition. Furthermore, the oxidation of the $\mathrm{Cr}(\mathrm{III})$ species to a $\mathrm{Cr}(\mathrm{VI})$ species must cease in the absence of a corrosive environment. This would be a very clear and unequivocal example of synergistic behavior (that is the efficiency of a combination of corrosion inhibitor components being greater than the sum of their individual efficiencies).

The ability of a combination of corrosion inhibitor pigment components to interact "synergistically" has been studied previously and work has focused on rare earth based inhibitor pigments with $\mathrm{Cr}(\mathrm{VI})$ based pretreatment layers, ${ }^{13}$ and zinc phosphate inhibitor pigments with calcium exchanged silica pigments. ${ }^{14}$ However, no mathematically well-defined analysis of the degree of synergism was attempted in either of these cases. The "chromate generating coatings" suggests itself as an ideal model system for the development and evaluation of such an analysis.

A number of methodologies exist by which the synergistic effect of inhibitor combinations might be analyzed. Many authors have taken the approach of Arakami and Hakerman ${ }^{15}$ whereby the synergistic behavior of the mixture of two inhibitors is observed when $S>1$ (where $\mathrm{S}$ is the synergistic parameter defined by Equation 1).

$$
\begin{gathered}
S=\frac{\left(1-E_{1+2}\right)}{\left(1-E_{12}\right)} \\
E_{1+2}=\left(E_{1}+E_{2}\right)-\left(E_{2} \times E_{2}\right)
\end{gathered}
$$

$E_{1}, E_{2}, E_{12}$ are the inhibition efficiency values associated with inhibitor 1 , inhibitor 2 , or a mixture of the two respectively, and are calculated using empirical data. ${ }^{16,17}$ Whilst this methodology can be used to quantify the level of synergy, it cannot be used to predict $S$ under different conditions, for example in the case that the concentration of one, or both, inhibitor varies from that used experimentally.

Following another approach, a combinatorial matrix of four rare earth chloride mixtures was used to evaluate the inhibition of AA2024 corrosion occurring during immersion in sodium chloride $(\mathrm{NaCl}){ }^{18}$ Potentiodynamic polarization and electrochemical impendance spectroscopy (EIS) were used to determine the corrosion current density $\left(i_{\text {corr }}\right)$ and polarization resistance $\left(R_{p}\right)$ associated with AA2024 samples in the presence of combinations of four lanthanide chlorides. The values obtained were used as input for combinatorial evaluation. A variety of models, used for predicting the optimal composition of inhibitor mixtures, were subsequently created. ${ }^{18}$ Whilst significant trends were observed during this work, predictions varied with the modelling approach employed. 
In the work described here we attempt to quantify the synergistic behavior (or not) of two corrosion inhibitors, used in combination, by adapting Loewe's isobolograms. Loewe first used isobolograms to demonstrate the synergy, additivity or antagonism of drugs used in combination. ${ }^{19-22}$ Isoboles show the drug dose combinations required for a given effect and has since been used as the basis for most contemporary treatments of drug-drug interactions. The use of such a graphical method allows for quick visualization of the level of interaction between two drugs at different dosages and the determination of regions of maximum synergy that maybe worth further investigation. $^{23}$

The system selected for use as an experimental model is one particular implementation of the "chromate generating coating" system. This implementation consists of an organic coating applied to the zinc surface of hot dip galvanised steel (HDG). The organic coating consists of polyvinyl butyral (PVB) in which is dispersed a combination of two cation-exchange corrosion inhibitor pigments. These pigments are both based on a cross-linked polystyrene sulfonate resin (Amberlite IR $120 \mathrm{H}^{+}$form). The first is exchanged with $\mathrm{Cr}^{3+}$ cations (the $\mathrm{Cr}$ (III) source) and the second with $\mathrm{Ce}^{4+}$ cations (previously suggested as a suitable oxidizing agent). ${ }^{8}$ The effectiveness of such pigments to release inhibitory cations has been demonstrated elsewhere. ${ }^{24,25}$ The redox kinetics by which $\mathrm{Ce}^{4+}$ oxidises $\mathrm{Cr}^{3+}$ (in the absence of a catalyst) has previously been characterised during a comprehensive kinetic study. ${ }^{26}$

The particular corrosion process investigated is the corrosion driven cathodic delamination of an organic coating. Cathodic delamination requires the presence of an electrolyte which contains group I cations (with hydrolytic stability and solubility at high $\mathrm{pH}$ ) which can support a strongly alkaline electrolyte. ${ }^{27,28}$ Anodic dissolution occurs in the region of the defect where the underlying metal is exposed. This is coupled to the ORR which occurs at the cathodic delamination front and is responsible for disbondment of the organic coating from the metal substrate..$^{27,28}$ This is an economically important problem on HDG and the effect of in-coating chromate on cathodic delamination has been well characterized. ${ }^{10}$ Polyvalent metal cations such as $\mathrm{Cr}^{3+}$ and $\mathrm{Ce}^{4+}$ are readily hydrolysed under the alkaline conditions which prevail in the underfilm electrolyte and, as such, can reasonably be expected to act as precipitation cathodic inhibitors when used in isolation. The question to be answered here is whether it is possible to convincingly demonstrate that their action, when used in combination, is additive, antagonistic, or indeed synergistic. In so doing we make use of two techniques. In all cases the corrosion product formed is clearly visible in the underfilm region beneath the organic coating and this means that time lapse photography can be used to follow coating delamination. Multiple samples can be imaged during each experiment which means that a vast amount of quantitative information can be obtained regarding the effect of various $\emptyset_{\text {pig }}$ combinations on the kinetics of cathodic delamination. A limited number of inhibitor pigment $\emptyset_{\text {pig }}$ combinations are then selected for study using the scanning Kelvin probe (SKP). The reason for using the SKP is twofold. Firstly, its capability to quantify the rate of the cathodic delamination of organic coatings is well established and has been demonstrated previously ${ }^{10,27,28}$ and it can therefore be used to confirm whether the delamination rates obtained optically are similar to those obtained potentiometrically. Secondly, the SKP is used to ascertain the effect, if any, that the inhibitor systems have on the characteristic potentials measured within the cathodic delamination cell. This mechanistic information can be used to judge the ability of pigments to behave as net anodic, or cathodic, inhibitors.

\section{Experimental}

Materials.-HDG steel was obtained from Tata Steel UK. These were $0.7 \mathrm{~mm}$ thick and coated on both sides with $20 \mu \mathrm{m}$ of zinc containing $0.15 \mathrm{wt} \%$ aluminum. Polyvinyl butyral-co-vinyl alcoholco-vinylacetate (PVB), molecular weight 70,000-100,000, chromium (III) chloride hexahydrate, cerium (IV) sulfate hydrate (complex with sulfuric acid), Amberlite IR $120 \mathrm{H}^{+}$form, and all other chemicals were obtained from Sigma Aldrich Chemical Co. and of analytical grade purity.

Methods.-Samples of HDG were polished using Buehler $5 \mu \mathrm{m}$ abrasive alumina powder and subsequently rinsed using distilled water and ethanol.

Pigment preparation.-Stock solutions of chromium (III) chloride hexahydrate and cerium (IV) sulfate hydrate were prepared at $0.5 \mathrm{M}$ concentration using distilled water. The same cation exchange resin, Amberlite IR120 $\left(\mathrm{H}^{+}\right.$form $)$, was used for the production of both $\mathrm{Cr}^{3+}$ and $\mathrm{Ce}^{4+}$ based inhibitor pigments. In each case, $100 \mathrm{ml}$ of the relevant stock solution was added to every $10 \mathrm{~g}$ of Amberlite IR $120\left(\mathrm{H}^{+}\right.$form $)$ resin beads. A magnetic stirrer was used to mix the solution/bead dispersions for 2 hours, after which the liquid phase was decanted and replaced with fresh stock solution. This process was repeated before leaving the mixture to stir overnight. Finally, a Buchner filter system was used to remove the beads, which were rinsed with distilled water. They were dried at $40^{\circ} \mathrm{C}$ for 12 hours before being milled for 1 hour at 350 RPM using a Retsch planetary ball miller. A $20 \mu \mathrm{m}$ mesh was used to sieve the resulting powder.

Coating preparation.-The mass of pigment $\left(M_{\text {pig }}\right)$ that corresponded to each pigment volume fraction $\left(\emptyset_{\text {pig }}\right)$ was calculated using Equation 3, where $M_{\text {pol }}$ is the mass of the polymer (in this case PVB), $\rho_{\text {pig }}$ is the density of the relevant pigment $\left(1.2 \mathrm{~g} . \mathrm{cm}^{-3}\right)$ and $\rho_{\text {pol }}$ is the density of the polymer $\left(1.083 \mathrm{~g} . \mathrm{cm}^{-3}\right)$.

$$
M_{p i g}=\frac{\varphi_{p i g} \times M_{p o l} \times \rho_{p i g}}{\left(1-\varphi_{p i g}\right) \times \rho_{p o l}}
$$

The pigment was then used to form an ethanolic slurry, before being dispersed into the relevant volume of ethanolic $15.5 \% \mathrm{w} / \mathrm{w}$ PVB solution using a high shear mixer, and degassed using a sonicating bath. Two types of sample were produced. In the case of the first type (on glass), electrical tape was placed on a glass microscope slide and acted as a height guide. The PVB was then bar cast onto the glass and the air dried film thickness, as measured using a screw gauge, was $30 \mu \mathrm{m}$. The second type of sample (shown in Figure 1) was prepared following the work of Stratmann. ${ }^{27,28}$ As such, the tape was applied to two parallel edges of a HDG sample surface before application of the PVB to produce a $30 \mu \mathrm{m}$ coating as above. A $10 \mathrm{~mm} \times 10 \mathrm{~mm}$ area of bare metal was exposed by partially peeling back the PVB coatings, and acted as an artificial coating defect from which corrosion driven coating disbondment could initiate. Residual clear adhesive tape with a PVB overcoat formed a barrier between the defect and intact coating. Non-corrosive silicone rubber was used to line the remaining three edges to produce an electrolyte well.

Corrosion driven delamination studies.-All corrosion driven cathodic delamination measurements were performed on coated HDG samples maintained at $96 \% \mathrm{RH}$ in air at RTP. The RH was maintained using air-contacting reservoirs of $0.86 \mathrm{M}$ aqueous $\mathrm{NaCl}$ "reference" solution. When required, corrosion was initiated by addition of a $2 \mathrm{~cm}^{3}$ aliquot of $0.86 \mathrm{M} \mathrm{NaCl}$ to the coating defect electrolyte well. The progress of cathodic delamination was followed using either time lapse photography or SKP.

During time lapse photography samples were placed in an air tight container which was itself placed in a Ortery Photosimile 200 software operated photography studio in which the lighting conditions were controlled. A transparent window in the container allowed for imaging of the samples using a Canon EOS 600D SLR camera. Images were acquired immediately after initiation and every two hours thereafter. The dark corrosion product formed during the cathodic delamination of PVB from a HDG substrate is clearly visible, and meant that the cathodic delamination front could be located easily using pixel value analysis in Adobe Photoshop. Each pixel corresponded to a distance of $30 \mu \mathrm{m}$ meaning that the position of the delamination front could be resolved to a high degree. In few cases the non-uniformity of the 


\section{0 hour intervals}
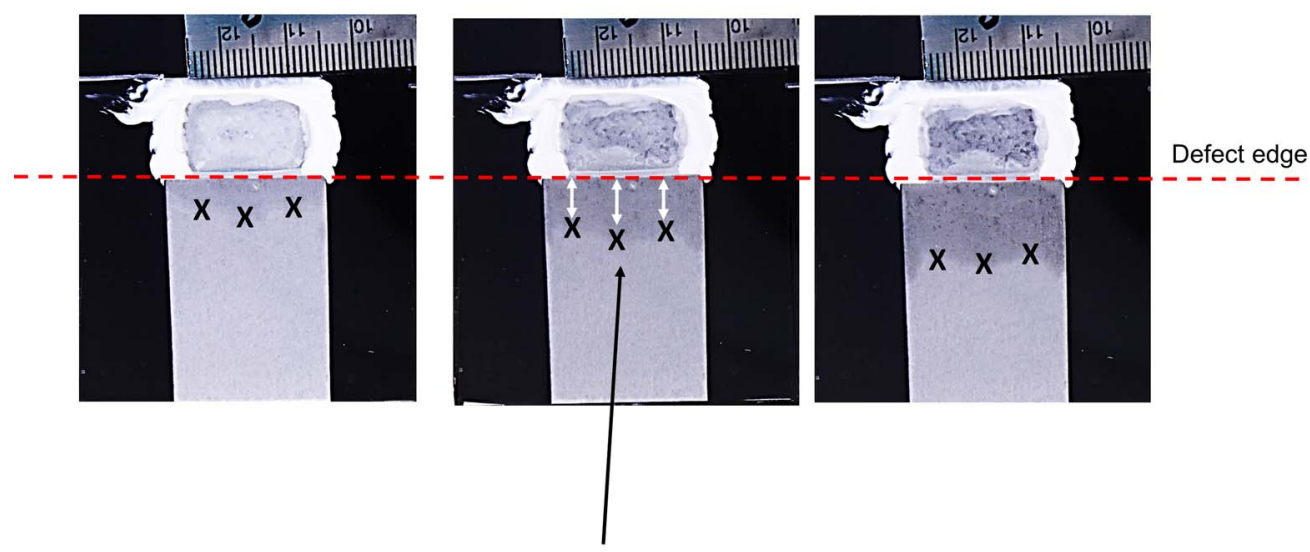

Distance to delamination

front taken in 3 places

5.65

Figure 1. Photograph showing an example of a 'Stratmann'21,22 delamination cell used during time lapse photography and the methodology used to calculate rate of coating disbondment.

coating delamination meant that the delaminated distance (distance from the defect, $x_{d e l}$ ) varied across the delamination front (see Figure 1) at any given time point. In these instances, the geometry of the front did not change with time and the rate of coating delamination was therefore considered to be independent of delamination front location. However, in an attempt to ensure that data collected was reliable and repeatable, three measurements were taken at different points along the delamination front (as shown in Figure 1). At least three samples were tested for each $\emptyset_{p i g}$ combination. The size of the container meant that a range of inhibitor $\emptyset_{\text {pig }}$ values could be investigated simultaneously and a delamination rate could subsequently be obtained for each coating pigment combination.

SKP measurements were only carried out for samples coated in PVB containing the highest experimental $\emptyset_{\text {pig }}(0.1)$. The methodology to calibrate the SKP in order to obtain the corrosion potential value associated with the metal surface beneath the polymer coating has been described in detail previously. ${ }^{10} \mathrm{Ag} / \mathrm{Ag}^{+}, \mathrm{Cu} / \mathrm{Cu}^{2+}, \mathrm{Fe} / \mathrm{Fe}^{2+}$, and $\mathrm{Zn} / \mathrm{Zn}^{2+}$ couples were used to calibrate the SKP in terms of electrode potential. Wells ( $1 \mathrm{~mm}$ deep, $8 \mathrm{~mm}$ in diameter) were machined out of the metal disks ( $5 \mathrm{~mm}$ thick, $15 \mathrm{~mm}$ in diameter), which were then filled with $0.5 \mathrm{M}$ aqueous solution of the relevant metal chloride salt (in the case of $\mathrm{Ag}$ a nitrate salt was used). The value of the Kelvin potential $\left(E_{K P}\right)$ was recorded at a height of $100 \mu \mathrm{m}$ above the meniscus of the electrolyte in the center of the well. A Solatron 1280 potentiostat was also used to measure the potential. A $30 \mu \mathrm{m}$ thick film of PVB was placed over each disk in order to determine the influence of PVB on the calibration. Once the polymer had equilibrated with the electrolyte a value was recorded.

The half-cell potential $\left(E_{1 / 2}\right)$ of the metal/electrolyte interface in the case that a bare metal surface is covered by a solution is given by Equation $4^{28,29}$

$$
E_{1 / 2}=\frac{\alpha_{e}^{r e f}}{F}-\chi_{g a s}^{\text {sol }}+\Delta \psi_{\text {sol }}^{r e f}
$$

where $\alpha_{e}^{r e f}$ is the electronic work function of the reference probe material, $F$ is the Faraday constant, $\chi_{\text {gas }}^{\text {sol }}$ is the dipole potential of the solution/gas interface, and $\Delta \psi_{\text {sol }}^{\text {ref }}$ is the Volta potential difference measured between the reference probe and the solution surface. In the case that the metal substrate is covered in a polymer coating Equation 5 applies

$$
E_{1 / 2}=\frac{\alpha_{e}^{r e f}}{F}-\chi_{g a s}^{p o l}+\Delta \psi_{p o l}^{r e f}
$$

where $\chi_{g a s}^{\text {pol }}$ is the dipole potential of the polymer/gas interface, and $\Delta \psi_{\text {pol }}^{r e f}$ is the Volta potential difference measured between the reference probe and the polymer surface. ${ }^{28,29}$ A layer of electrolyte will exist between the metal substrate and the polymer following its disbondment and an additional term $\left(\Delta \varphi_{D}\right)$ is added to Equation 5. ${ }^{28,29}$

$$
E_{1 / 2}=\Delta \varphi_{D}+\frac{\alpha_{e}^{r e f}}{F}-\chi_{\text {gas }}^{\text {pol }}+\Delta \psi_{\text {pol }}^{r e f}
$$

$\Delta \varphi_{D}$ is the Donnan potential equivalent to the Galvani potential difference between the polymer layer and electrolyte solution $\left(\varphi^{\text {sol }}-\varphi^{\text {pol }}\right)$. The remaining terms within Equation 6 are expected to remain constant with time if the gas-phase composition does not change. The presence of ion exchange membranes can result in the polymer exhibiting a fixed charge. In this case, a Donnan potential term is given by Equation $7^{10,28,29}$

$$
\Delta \varphi_{D}=\frac{R T}{F} \ln \left\{\frac{x}{2}+\sqrt{1+\left(\frac{x}{2}\right)^{2}}\right\}
$$

where $T$ is the temperature, $R$ is the gas constant and $x$ is the ratio between the membrane fixed charge density and the electrolyte concentration.

To determine the role of the Donnan potential term, calibration was conducted in the case that the cation exchange pigment was both present (at $0.1 \emptyset_{\text {pig }}$ ) and absent from the PVB film. Figure 2 shows the Kelvin probe potential $\left(E_{K P}\right)$ measured $100 \mu \mathrm{m}$ above films containing the different pigments for a one hour time period. The value of $E_{K P}$ observed is ca. $0.15 \mathrm{~V}$ higher in the case of all pigmented coatings, compared to unpigmented PVB. In comparison, the Donnan contribution has been deemed insignificant in the case of silica and bentonite cation exchange pigments during previous work. ${ }^{30}$

During the study of cathodic coating disbondment, the SKP reference probe was scanned along a $12 \mathrm{~mm}$ line, normal to the boundary between the coating and the defect, at which it was terminated. Successive scans were taken at 1 hour intervals thereafter. A constant SKP chamber humidity of ca. $96 \% \mathrm{RH}$ was ensured by using reservoirs of $0.86 \mathrm{M}$ aqueous $\mathrm{NaCl}$ reference solutions. The temperature remained constant at $20^{\circ} \mathrm{C}$.

\section{Results}

Time lapse results.-A time lapse photography technique was utilized in order to obtain quantitative information regarding the effect of various inhibitor pigment concentration combinations on the rate of 


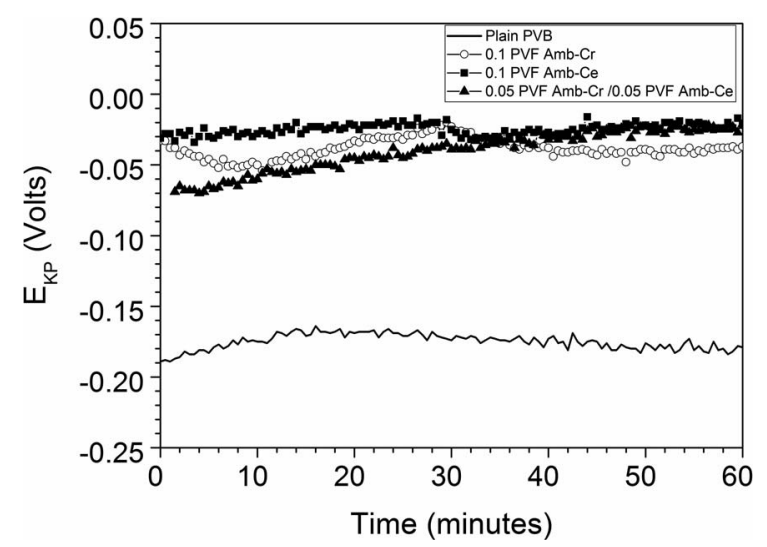

Figure 2. SKP derived $E_{K P}$ recorded $100 \mu \mathrm{m}$ above a copper calibration disk covered in self supporting unpigmented and pigmented PVB films.

cathodic disbondment. Amb-Ce and Amb-Cr pigments were dispersed within PVB at the $\emptyset_{\text {pig }}$ values shown in Table I. Corrosion driven coating delamination was initiated using $0.86 \mathrm{M} \mathrm{NaCl}$ and photos were taken every two hours. Cathodic delamination typically became initiated in all cases and the extent of cathodic coating delamination on the coated HDG samples was clearly visible in the time lapse photography images. A typical image is shown in Figure 1. The distance over which delamination $\left(x_{d e l}\right)$ had occurred was estimated by recording the distance between the delamination front and the defect edge at three points along the delamination front (as shown in Figure 1). At least three experiments were conducted for each $\emptyset_{\text {pig }}$ combination. The kinetics of delamination could then be followed by plotting $x_{d e l}$ as a function of time. Figure 3 shows an example of the type of graph obtained for the case that a.) Amb-Cr $\emptyset_{\text {pig }}$ was varied and Amb-Ce $\varnothing_{\text {pig }}$ $=0$ and b.) When the total $\emptyset_{\text {pig }}$ was 0.025 . A typical data set is shown for each $\emptyset_{\text {pig }}$. The delamination rates, obtained using linear regression, along with the corresponding inhibition efficiency, are shown in Table I. The confidence limits (errors) shown correspond to \pm one unit of standard deviation on the mean of a series of delamination rates (slopes) obtained from a series of duplicate experiments.

$S K P$ results.-Delamination of unpigmented $P V B$ coatings.Baseline kinetics were initially obtained by studying the delamination of uninhibited PVB from a HDG substrate. At the end of the experimental time period the location of the delamination front was determined using the $E_{\text {corr }}$ profiles obtained. The sample was then taken out of the SKP chamber and imaged using the time lapse photography technique (Figure $4 \mathrm{~b}$ ) to confirm whether the delamination

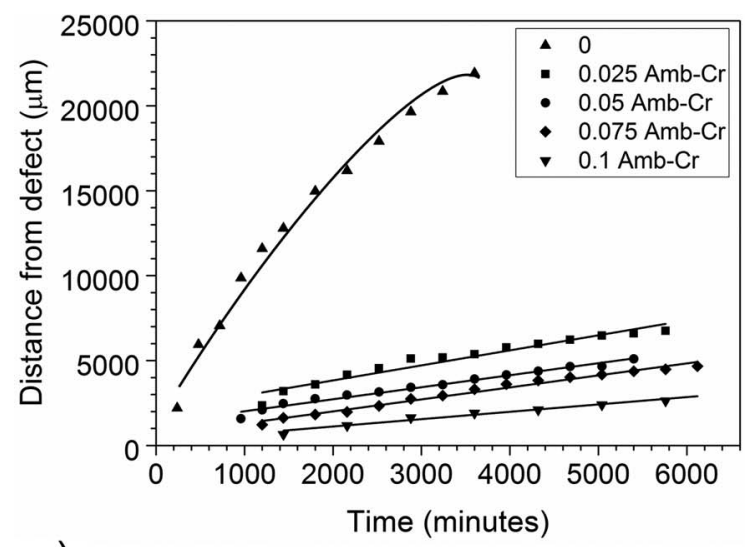

a.)

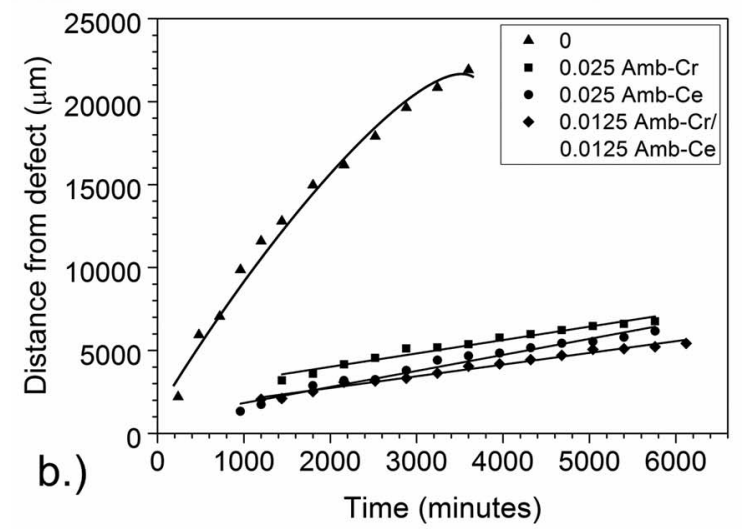

Figure 3. Time lapse photography derived distance from the defect $\left(x_{d e l}\right)$ as a function of time for the delamination of a PVB model coating pigmented with a.) varying Amb-Cr $\emptyset_{\text {pig }}$, and b.) total $\emptyset_{\text {pig }}$ of 0.025 , from a HDG substrate after initiation using a $0.86 \mathrm{M} \mathrm{NaCl}$ electrolyte.

rates obtained optically were similar to those obtained potentiometrically.

Detailed accounts of the cathodic delamination of an unpigmented PVB coating from HDG have been published elsewhere. ${ }^{10,24,25}$ Initially both $\mathrm{Na}^{+}$and $\mathrm{Cl}^{-}$(from the experimental electrolyte) can diffuse into the interface and a galvanic cell element does not exist. ${ }^{35}$ Time dependent $E_{\text {corr }}(x)$ profiles became established approximately 120 minutes $\left(t_{i}\right)$ after initiation and are shown in Figure $4 \mathrm{a}$. A uniform potential value of $-0.30 \mathrm{~V}$ vs. SHE $\left(E_{\text {intact }}\right)$ is observed over the intact coating

Table I. Time lapse photography derived linear rates $\left(\mu \mathrm{m} . \mathrm{min}^{-1}\right)$ at which PVB, pigmented with varying amounts of Amb-Cr and Amb-Ce, cathodically delaminates from a HDG substrate.

\begin{tabular}{|c|c|c|c|c|c|c|c|}
\hline \multicolumn{2}{|c|}{ Amb-Ce $\phi_{p i g}$} & \multirow[b]{2}{*}{0} & \multirow[b]{2}{*}{0.0125} & \multirow[b]{2}{*}{0.025} & \multirow[b]{2}{*}{0.05} & \multirow[b]{2}{*}{0.075} & \multirow[b]{2}{*}{0.1} \\
\hline & $\mathrm{b}-\mathrm{Cr} \emptyset_{p i g}$ & & & & & & \\
\hline \multirow[t]{2}{*}{0} & Rate $\mu \operatorname{mmin}^{-1}$ & $5.2 \pm 0.44$ & & $0.9 \pm 0.06$ & $0.7 \pm 0.05$ & $0.71 \pm 0.11$ & $0.9 \pm 0.01$ \\
\hline & Inhibition Efficiency & & & 0.82 & 0.87 & 0.86 & 0.83 \\
\hline \multirow[t]{2}{*}{0.0125} & Rate $\mu \mathrm{mmin}^{-1}$ & & $0.86 \pm 0.22$ & & & & \\
\hline & Inhibition Efficiency & & 0.84 & & & & \\
\hline \multirow[t]{2}{*}{0.025} & Rate $\mu \operatorname{mmin}^{-1}$ & $0.99 \pm 0.13$ & & $0.69 \pm 0.21$ & & & \\
\hline & Inhibition Efficiency & 0.81 & & 0.87 & & & \\
\hline \multirow[t]{2}{*}{0.05} & Rate $\mu \mathrm{mmin}^{-1}$ & $0.7 \pm 0.03$ & & & $0.46 \pm 0.20$ & & \\
\hline & Inhibition Efficiency & 0.86 & & & 0.91 & & \\
\hline \multirow[t]{2}{*}{0.075} & Rate $\mu \mathrm{mmin}^{-1}$ & $0.7 \pm 0.03$ & & & & & \\
\hline & Inhibition Efficiency & 0.87 & & & & & \\
\hline \multirow[t]{2}{*}{0.1} & Rate $\mu \operatorname{mmin}^{-1}$ & $0.4 \pm 0.02$ & & & & & \\
\hline & Inhibition Efficiency & 0.92 & & & & & \\
\hline
\end{tabular}



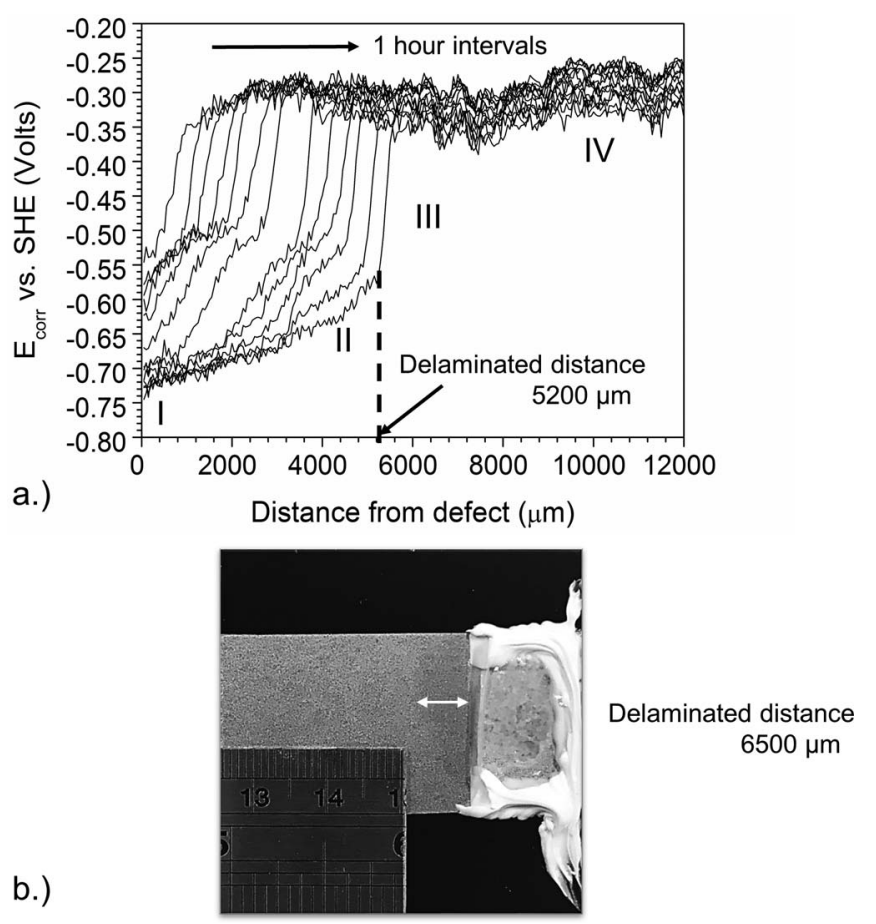

Figure 4. a.) SKP derived $E_{\text {corr }}$ as a function of distance from defect $\left(x_{d e l}\right)$ profiles for the delamination of a PVB model coating, from a HDG substrate after initiation using a $0.86 \mathrm{M} \mathrm{NaCl}$ electrolyte. $t_{i}=270$ minutes. Profiles are shown at 1 hour intervals and b.) Photograph of the sample taken immediately following recording of the final $E_{\text {corr }}$ profile shown in a.)

(Region IV) where zinc dissolution does not occur due to the absence of bulk electrolyte. The high permeability of the intact polymer layers to oxygen means that the rate of the ORR at the metal/polymer interface is kinetically faster than the anodic partial reaction, (which is slowed down due to the presence of a passive zinc hydr(oxide) layer). ${ }^{31}$ In comparison, in the near-defect region, the presence of a corrosive $\mathrm{NaCl}$ electrolyte results in dissolution of this hydr(oxide) film and $E_{c o r r}$ values fall to that expected in the case of freely corroding zinc (ca. $-0.7 \mathrm{~V}$ vs. SHE). ${ }^{10,30,31}$ A sharp transition between high (intact) and low (near-defect) potential values (the delamination front) can also be observed (Region III) and moves away from the defect with time. This potential jump (Region III) is commonly used as a means of determining $x_{d e l}$ and subsequently determine the kinetics associated with the disbondment process. The inhibition of anodic dissolution at the intact polymer interface results in the formation of a galvanic element in the region between the defect (Region I) and the delamination front (Region III). This galvanic coupling is facilitated by the migration of cations in the underfilm electrolyte and it is this ionic current which results in the ohmic potential drop shown in Region II. ${ }^{31}$ The ingress of alkali electrolyte $(\mathrm{pH} \geq 10)^{31}$ results in an increase in anodic activity and zinc begins to dissolve in the delaminated zone to form zincate. It seems likely that one mechanism of coating disbondment on zinc is the dissolution of the amphoteric air-formed surface oxide by the alkaline under-film electrolyte. ${ }^{32}$ It is also possible that the alkaline electrolyte displaces the coating ${ }^{33}$ or that base catalyzed hydrolysis of vinyl acetate functions occurs within the PVB.

Time-dependent $x_{d e l}$ was obtained by locating the point of highest potential gradient in the relevant $E_{\text {corr }}$ delamination profiles shown in Figure $4 \mathrm{a}^{10,27,28}$ and was $(5200 \pm 500) \mu \mathrm{m}$. In comparison, a time lapse photography image (Figure $4 \mathrm{~b})$ showed $x_{d e l}$ to be $(6500 \pm 600)$ $\mu \mathrm{m}$. At this point it should be considered that there was a small time delay between recording the SKP data and acquisition of the photograph, during which the delamination front may have propagated a small distance. Secondly, although maximum care was taken to ensure that the SKP measurements were recorded over the same part of

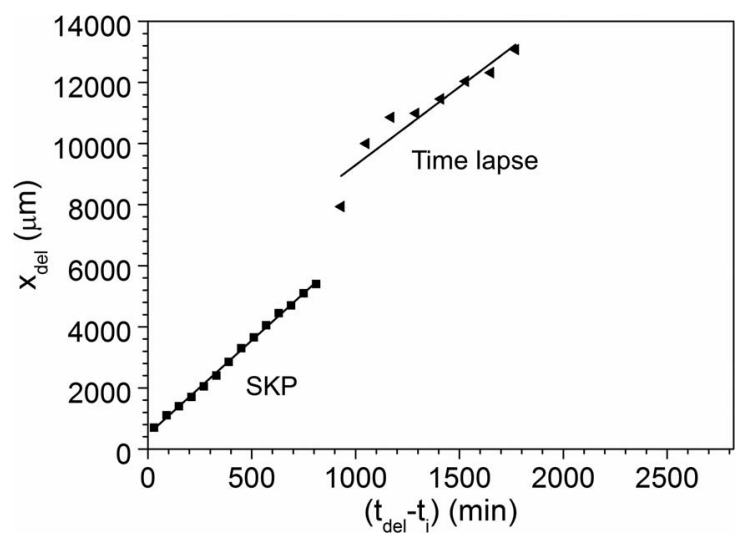

Figure 5. Distance that an unpigmented PVB coating has delaminated from the defect $\left(x_{d e l}\right)$ as a function of time, as derived from both SKP and time lapse photography.

the sample from which $x_{d e l}$ was optically determined, it is possible that measurements were taken from slightly different locations along the delamination front. However, going forward, this effect is believed to be minimized by taking measurements at various locations along the delamination front. Other possible sources of error in the value of $x_{d e l}$ obtained from the two techniques may include any time delay which exists between changes in the potential values (as measured by the SKP) and the formation of visible corrosion product. Nevertheless, $x_{d e l}$, obtained using time lapse microscopy, is considered to be within error of that recorded using the SKP. Time lapse microscopy is therefore considered a robust means by which to acquire a vast amount of quantitative information regarding the effect of various $\emptyset_{\text {pig }}$ combinations on the kinetics of cathodic delamination. The further delamination of the coating from the sample was subsequently monitored using time-lapse photography and the rate of disbondment was compared to that obtained when using the SKP (Figure 5).

The rate of a multistep process such as cathodic delamination (occurring after establishment of a galvanic cell) may become limited by any one of a number of processes (whichever is the slowest or kinetically most difficult). These processes include; cathodic oxygen reduction, oxygen diffusion, underfilm ion migration and the anodic dissolution of metal. ${ }^{32,34}$ In the case of the cell used here, the penetrative organic coating defect (the principal site of anodic metal dissolution) is physically large and it is therefore very unlikely that the system should become anodically limited. For uninhibited organic coating systems, (in the absence of inhibitor pigments or pretreatements) the rate of though-coating oxygen diffusion and oxygen reduction are expected to be fast. Under these conditions the kinetics of coating delamination are ohmically controlled by ionic conduction in the electrolyte film ingressing beneath the delaminated coating and they are typically parabolic $\left(x_{d e l}\right.$ increases with $\left.t^{1 / 2}\right)$. It has previously been shown that such parabolic kinetics are principally controlled by the mobility of cations (here $\mathrm{Na}^{+}$) within the electrolyte film ${ }^{35,36}$ When inhibitor pigments and/or pretreatments are present (which will be the case for any real coating system, or realistic model thereof) the rate of the cathodic delamination is likely to be controlled by the rate of interfacial electron transfer processes associated with though-coating cathodic oxygen reduction and very unlikely to be limited by rates of underfilm cation migration. ${ }^{37}$ Under these circumstances delamination kinetics are predicted to be linear, that is to say the rate of delamination will be independent of $x_{d e l}$, which will increase linearly with respect to time.

In this work the initial linear rate of coating delamination is used for purposes of comparison. During the initial experimental time period the diffusion length will be quite small and diffusion of cations cannot be the rate limiting step. ${ }^{34,35}$ The $k_{d}$ value obtained by analyzing the SKP data was $6.16 \mu \mathrm{m} \cdot \mathrm{min}^{-1}$. In the case of time lapse photography data the value obtained was $5.12 \mu \mathrm{m} . \mathrm{min}^{-1}$. The two results (Figure 5) are within error of one another and we are therefore confident that time 


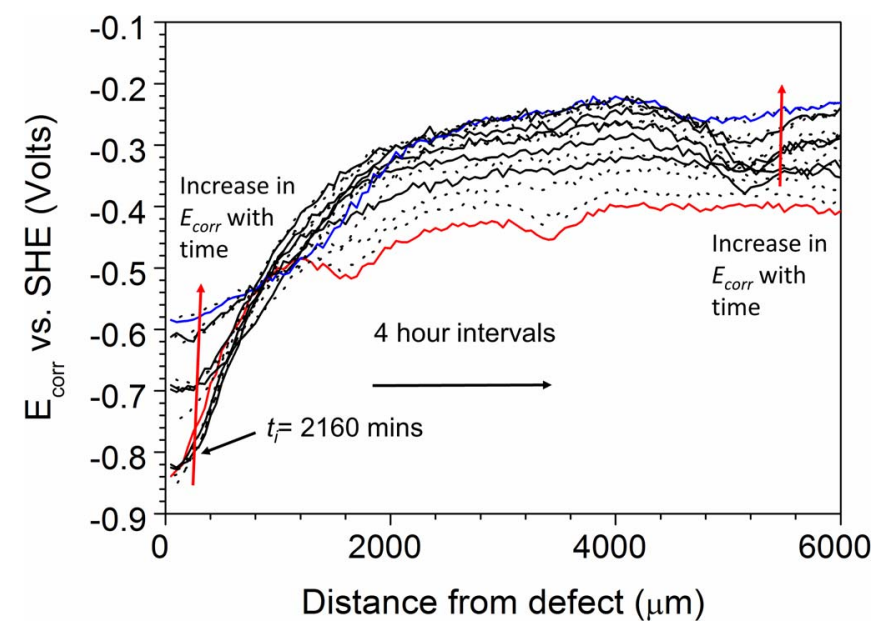

Figure 6. SKP derived $E_{\text {corr }}$ as a function of distance from defect $\left(x_{d e l}\right)$ profiles for the delamination of a PVB model coating pigmented with $0.1 \varnothing_{\text {pig }} \mathrm{Amb}-\mathrm{Ce}$, from a HDG substrate after initiation using a $0.86 \mathrm{M} \mathrm{NaCl}$ electrolyte. $t_{i}=$ 2160 minutes. Profiles are shown at 4 hour intervals. Initial profile shown in red. Final profile shown in blue.

lapse photography can be used quantitatively to provide information regarding coating delamination rate.

The mechanism by which corrosion inhibitive pigments offered corrosion protection was investigated by acquiring electrochemical potential distributions using the SKP technique. Figure 6 shows the time dependent $E_{\text {corr }}(x)$ profiles established in the case that the PVB coating is pigmented with $0.1 \varnothing_{\text {pig }}$ Amb-Ce. Initially, the $E_{\text {intact }}$ and $E_{c o r r}$ values are similar to those observed in the case of unpigmented PVB (Figure 4). As time progresses the potential within the delaminated zone increases from ca. $-0.8 \mathrm{~V}$ vs. SHE to ca. $-0.6 \mathrm{~V}$ vs. SHE. On the basis of mixed potential theory, this is indicative of the inhibition of the partial anodic reaction (for example zincate production) in the underfilm region. ${ }^{31} \mathrm{~A} \sim 0.2 \mathrm{~V}$ increase in $E_{\text {intact }}$ occurs in parallel to the increase observed within the delaminated zone. The increase in potential with time is consistent with the release and presence of the $\mathrm{Ce}(\mathrm{IV})$ based oxidizing agent.

Time dependent $E_{\text {corr }}(x)$ profiles established in the case that the PVB coating is pigmented with $0.1 \emptyset_{\text {pig }}$ Amb-Cr are shown in Figure 7. The potential values observed within the defect are slightly higher (ca. $-0.6 \mathrm{~V}$ vs. SHE) than those observed in the case of uninhibited PVB (Figure 4). In comparison $E_{\text {intact }}$ varies considerably from that observed in Figure 4 and decreases to $\sim-0.7 \mathrm{~V}$ vs. SHE. This value is

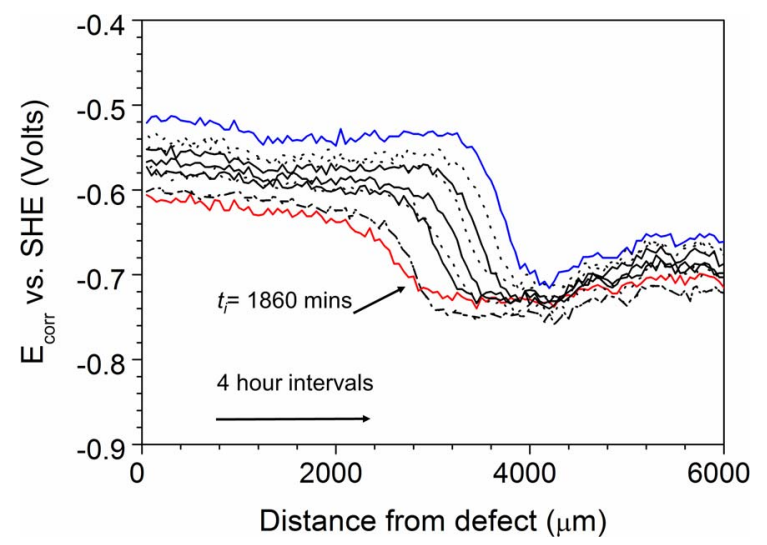

Figure 7. SKP derived $E_{\text {corr }}$ as a function of distance from defect $\left(x_{\text {del }}\right)$ profiles for the delamination of a PVB model coating pigmented with $0.1 \emptyset_{\text {pig }} \mathrm{Amb}-\mathrm{Cr}$, from a HDG substrate after initiation using a $0.86 \mathrm{M} \mathrm{NaCl}$ electrolyte. $t_{i}=$ 1860 minutes. Profiles are shown at 4 hour intervals. Initial profile shown in red. Final profile shown in blue.

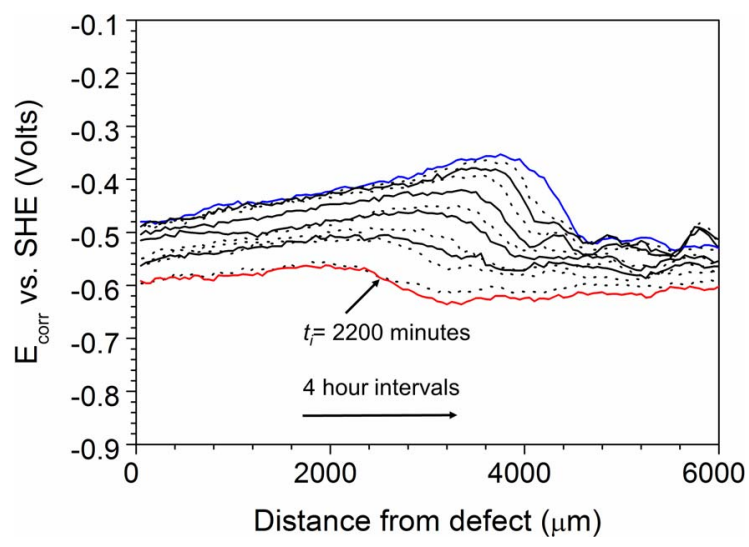

Figure 8. SKP derived $E_{c o r r}$ as a function of distance from defect $\left(x_{d e l}\right)$ profiles for the delamination of a PVB model coating pigmented from $0.05 \varnothing_{\text {pig }}$ Amb$\mathrm{Ce}$ and $0.05 \emptyset_{\text {pig }}$ Amb-Cr, from a HDG substrate after initiation using a $0.86 \mathrm{M}$ $\mathrm{NaCl}$ electrolyte. $t_{i}=2200$ minutes. Profiles are shown at 4 hour intervals. Initial profile shown in red. Final profile shown in blue.

$\sim 0.4 \mathrm{~V}$ lower than that observed in the case of an unpigmented coating (Figure 4) and is not consistent with the value of the Donnan potential contribution shown in Figure 2. It is therefore inferred that the drop in potential is a result of cathodic inhibition prior to coating disbondment. The delamination front is undetectable during the initial stages of delamination but become more pronounced as time progresses.

The $E_{\text {corr }}(x)$ profiles established in the case that the PVB coating is pigmented with $0.05 \varnothing_{\text {pig }}$ Amb-Ce and $0.05 \emptyset_{\text {pig }}$ Amb-Cr (Figure 8) are palpably different. The near-defect potential is similar to that observed in the case of PVB coatings containing $0.1 \emptyset_{\text {pig }}$ Amb- $\mathrm{Cr}(\sim-0.6 \mathrm{~V}$ vs. $\mathrm{SHE}$ ). There is a steady $\sim 0.1 \mathrm{~V}$ increase in potential from the defect to the delamination front, at which it reaches its highest value of $\sim-0.35 \mathrm{~V}$ vs. SHE. This is consistent with the release of oxidizing $\mathrm{Ce}^{4+}$ cations from the ion exchange resin, and the subsequent presence of 'transient' $\mathrm{CrO}_{4}{ }^{2-}$, upon contact with the corrosive $\mathrm{NaCl}$ electrolyte. The delamination front is again indiscernible during the initial stages of delamination but becomes more pronounced as time progresses.

Due to the complexity of the systems studied it is unclear whether the long initiation time observed for pigmented coatings (Figure 7 and Figure 8 ) is due to the ability of the inhibitive pigments to delay the onset of coating delamination, or a consequence of limitations of the SKP in detecting the delamination front. The deviation in appearance of the profiles obtained in the presence of Amb-Ce and Amb-Cr, from those typically expected (such as in Figure 4), means that they are deemed unsuitable for quantitative use. In an attempt to determine the source of this deviation, an effort was made to quantify the contribution of the Donnan potential to the potential value recorded. Figure 2 shows that the potential measured in the presence of ion exchange pigments varies $\sim 0.15 \mathrm{~V}$ from that observed in the case of unpigmented PVB. This variation is constant for all inhibitor systems tested and is not believed to play a significant role in the development of the $E_{c o r r}$ profiles shown in Figure 6 to Figure 8.

\section{Discussion}

Cathodic delamination of $P V B$ containing Amb-Ce.-In all cases, the delamination rates of pigmented PVB coatings were significantly less than that obtained in the case of unpigmented PVB (Table I). The ability of Amb-Ce (when used in isolation) to inhibit the delamination of PVB is unpredictable due to its properties as a facile oxidizing agent which may therefore act to accelerate corrosion driven coating disbondment. However, it is possible that its reduction via Equation 8 partially replaces the cathodic oxygen reduction reaction. Secondly the increase of $\mathrm{pH}$ (to values of approximately $10,{ }^{31}$ ) upon delamination, will result in a hydrolysis reaction given by Equation 10. Insoluble 
ceria would then form via a precipitation reaction (Equation 11). The complexity of the $E_{\text {corr }}$ profiles obtained (Figure 6) is believed to be a consequence of the varying reactions which may take place. ${ }^{38}$

$$
\begin{gathered}
{\left[\mathrm{Ce}\left(\mathrm{H}_{2} \mathrm{O}\right)_{6}\right]^{3+} \leftrightarrow\left[\mathrm{Ce}\left(\mathrm{H}_{2} \mathrm{O}\right)_{5}(\mathrm{OH})\right]^{3+}+\mathrm{H}^{+}+e^{-}} \\
E_{0}=1.715-0.0591 \mathrm{pH}+0.0591 \log \frac{\left[[\mathrm{Ce}(\mathrm{OH})]^{3+}\right]}{\left[\mathrm{Ce} e^{4+}\right]} \\
{\left[\mathrm{Ce}\left(\mathrm{H}_{2} \mathrm{O}\right)_{5}(\mathrm{OH})\right]^{3+} \leftrightarrow\left[\mathrm{Ce}\left(\mathrm{H}_{2} \mathrm{O}\right)_{4}(\mathrm{OH})_{2}\right]^{2+}+\mathrm{H}^{+}} \\
{\left[\mathrm{Ce}\left(\mathrm{H}_{2} \mathrm{O}\right)_{4}(\mathrm{OH})_{2}\right]^{2+} \leftrightarrow \mathrm{CeO}_{2}+2 \mathrm{H}^{+}+4 \mathrm{H}_{2} \mathrm{O}}
\end{gathered}
$$

The formation of insoluble corrosion products provides a barrier to electron transfer and in turn, a reduced corrosion rate.

Cathodic delamination of PVB containing Amb-Ce.-When the PVB coating is pigmented with solely Amb-Cr (Figure 7), it is possible that an insoluble $\mathrm{Cr}(\mathrm{OH})_{3(s)}$ corrosion product forms. The amphoteric nature of $\mathrm{Cr}(\mathrm{OH})_{3(s)}$ means that it is able to dissolve at values of low (Equation 12) and high $\mathrm{pH}$ (Equation 13). ${ }^{39}$

$$
\begin{aligned}
& \mathrm{Cr}(\mathrm{OH})_{3(s)} \leftrightarrow \mathrm{Cr}(\mathrm{OH})_{2(a q)}^{+}+\mathrm{OH}_{(a q)}^{-} \\
& K_{s}=5.8 \times 10^{-13} \mathrm{~mol}^{2} \mathrm{dm}^{-6} \\
& \mathrm{Cr}(\mathrm{OH})_{3(s)} \leftrightarrow \mathrm{CrO}_{2(a q)}^{-}+\mathrm{H}_{(a q)}^{+}+\mathrm{H}_{2} \mathrm{O} \\
& K_{s}=6.3 \times 10^{-16} \mathrm{~mol}^{2} \mathrm{dm}^{-6}
\end{aligned}
$$

Using the solubility products $\left(K_{s}\right)$ given by Equation 12 and Equation 13, and assuming that $\mathrm{Cr}(\mathrm{OH})_{3}$ remains insoluble for saturated concentrations of $\mathrm{Cr}(\mathrm{OH})_{2(a q)}^{+}$and $\mathrm{CrO}_{2(a q)}^{-}$below $10^{-5} \mathrm{~mol} . \mathrm{dm}^{-3}$, the $\mathrm{pH}$ range over which $\mathrm{Cr}(\mathrm{OH})_{3}$ remains insoluble can be predicted as pH 6.76-10.5.

Additions of $\mathrm{CrO}_{4}{ }^{-2}$ to the experimental electrolyte have previously resulted in anodic inhibition within the (Stratmann cell) defect region. ${ }^{10}$ However, the electric field associated with the delamination cell means that $\mathrm{CrO}_{4}{ }^{-2}$ ions are excluded from the underfilm electrolyte and significant resistance to cathodic delamination rate is only observed in the case that $\mathrm{CrO}_{4}{ }^{-2}$ based pigments exist within the coatings. ${ }^{10}$ The efficiency with which $\mathrm{CrO}_{4}{ }^{-2}$ is able to inhibit corrosion has previously been linked to its ability to irreversibly adsorb on metal and oxide surfaces ${ }^{10}$ and it has previously been shown that its incorporation into a coating leads to reduced rates of ORR on copper. ${ }^{6}$ Elsewhere it has been proposed that the ORR is partially replaced by $\mathrm{CrO}_{4}{ }^{-2}$ reduction. ${ }^{10}$

Cathodic delamination of PVB containing both Amb-Ce and $\boldsymbol{A m b}$ - $\boldsymbol{C r}$.- In the case that both Amb-Ce and Amb-Cr are used in combination (Figure 8) a different mechanism of inhibition is proposed. Prior to electrolyte exposure $\mathrm{Ce}^{4+}$ exists, water bound, within the acidic resin exchange medium in the coating. Upon exposure oxidising $\mathrm{Ce}^{4+}$ cations are released and reduction occurs via Equation 9. ${ }^{38}$ This process is consistent with the increase in potential observed in the region of the delamination front in Figure 8. This reduction reaction is coupled to $\mathrm{Cr}^{3+}$ oxidation (Equation 14) resulting in dichromate formation. This is only thermodynamically possible in the case that the potential given by Equation 9 exceeds that associated with Equation $15 .^{38}$

However, an increase in $\mathrm{pH}$ within the underfilm electrolyte ${ }^{31}$ can lead to competitive hydrolysis (Equation 10) and subsequent precipitation of insoluble ceria (Equation 11). This means that the formation of any inhibiting hexavalent oxy-anions (and therefore nonsoluble inhibiting specie) must occur either within the coating before exposure to the alkali catholyte, or quickly upon electrolyte exposure.

$$
\begin{gathered}
2 \mathrm{CrO}_{4(a q)}^{2-}+10 \mathrm{H}_{2} \mathrm{O}+6 e^{-} \leftrightarrow 2 \mathrm{Cr}(\mathrm{OH})_{3(s)}+10 \mathrm{OH}^{-} \\
E_{0}=1.244-0.0985 \mathrm{pH}+0.0197 \log \left[\mathrm{CrO}_{4}^{2-}\right]
\end{gathered}
$$

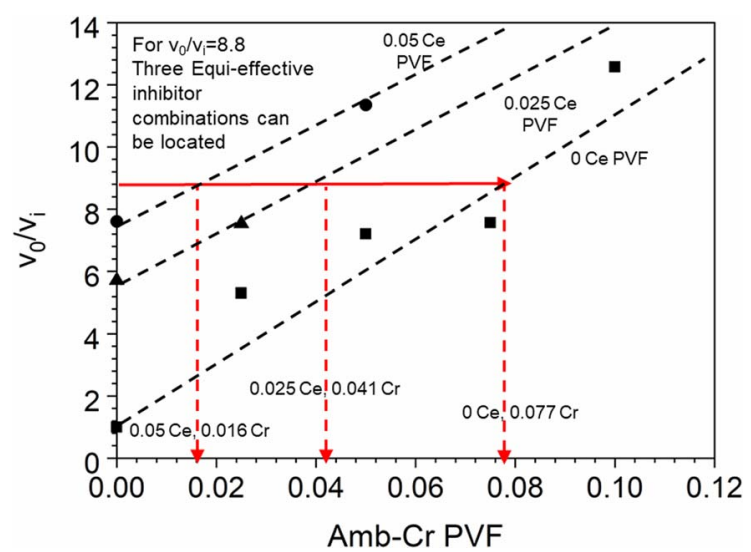

Figure 9. Relative inhibition efficiency $v_{o} / v_{i}$ plotted as a function of Amb-Cr $\emptyset_{\text {pig }}$ for various Amb-Ce $\emptyset_{\text {pig }}$ values.

Quantifying synergy.-The mechanism by which this system is proposed to work relies on the presence of both inhibitors (the first based on $\mathrm{Cr}(\mathrm{III})$ and the second on an oxidizing agent) within the coating. The interaction between such inhibitor pigments is therefore of significant interest. The approach taken to determine the synergistic/antagonistic nature of the corrosion inhibitor couple has been adapted from that used in the case of drug synergy and enzyme inhibition. ${ }^{19-23}$ As such, the efficiency of corrosion driven cathodic delamination resistance, offered by each pair of inhibitors, is graphically analyzed. Figure 9 shows plots of the $v_{o} / v_{i}$ (where $v_{o}$ is the rate of cathodic delamination in the absence of inhibitive pigments and $v_{i}$ is the rate in the presence of inhibitive pigments) as a function of Amb-Cr (inhibitor A) $\emptyset_{\text {pig }}$ in the case that Amb-Ce (inhibitor B) $\emptyset_{\text {pig }}$ is $0,0.025$ or 0.05 . Equi-efficient combinations of inhibitor $\emptyset_{\text {pig }}$ can be determined by locating the points at which a horizontal line (along which inhibition efficiency is constant) intercepts with a plotted curve (for which Amb-Ce is constant for each curve) as shown in Figure 9 . Each $v_{o} / v_{i}$ value can therefore be associated with a number of different inhibitor $\emptyset_{\text {pig }}$ mixtures. For example, in Figure 9, three combinations are associated with a $v_{o} / v_{i}$ value of 8.8. The assumption that the relationship between Amb-Cr $\emptyset_{\text {pig }}$ and $v_{o} / v_{i}$ is linear for all Amb-Ce $\emptyset_{\text {pig }}$ values allows for the construction of isoboles, shown in Figure 10.

In Figure 10 the $x$ and $y$ axis correspond to Amb-Cr $\emptyset_{\text {pig }}$ and Amb $\mathrm{Ce} \emptyset_{\text {pig }}$ respectively. Each data set (isobole) is associated with one $v_{o} / v_{i}$ value and equi-efficient corrosion inhibitor $\emptyset_{\text {pig }}$ combinations (which provide similar measurable resistance to corrosion driven cathodic delamination) can be deduced.

The methodology used for drug-synergy ${ }^{19-23}$ can be used for any inhibitor combination. Let $I \emptyset_{x, A}$ be the $\emptyset_{\text {pig }}$ of inhibitor A needed to provide an inhibition efficiency of X. Similarly $I \emptyset_{x, B}$ is the concentration of inhibitor B needed to provide an inhibition efficiency of $\mathrm{X}$. $\phi_{x, A}$ and $\emptyset_{x, B}$ are the concentrations of $\mathrm{A}$ and $\mathrm{B}$ respectively, needed to achieve an inhibition efficiency of $X$, when used in combination. The concentrations of inhibitor A and B which, in combination, provide the same effect can therefore be expressed as by Equation 16 where $\frac{I \phi_{x, A}}{I \phi_{x, B}}$ is the relative influence of the inhibitors and is assumed to be constant.

$$
\emptyset_{X, A}+\frac{I \emptyset_{X, A}}{I \emptyset_{X, B}} \emptyset_{X, B}=I \emptyset_{X, A}
$$

Let us say that the isobole in Figure 11 represents the fixed inhibition efficiency X. The concentration of $\mathrm{A}$ or $\mathrm{B}$ (when used in isolation) at which $\mathrm{X}$ occurs are indicated at $\left(0, I \emptyset_{x, A}\right)$ and $\left(I \emptyset_{x, B}, 0\right)$. The line joining these points can be referred to as the line of additivity where the gradient of the line is equal to $\frac{I \phi_{X, A}}{I \phi_{X, B}}$. The efficiency is constant $(\mathrm{X})$ for all $\left(\phi_{A}, \phi_{B}\right)$ pairs which fall on this line and Equation 17 (where 


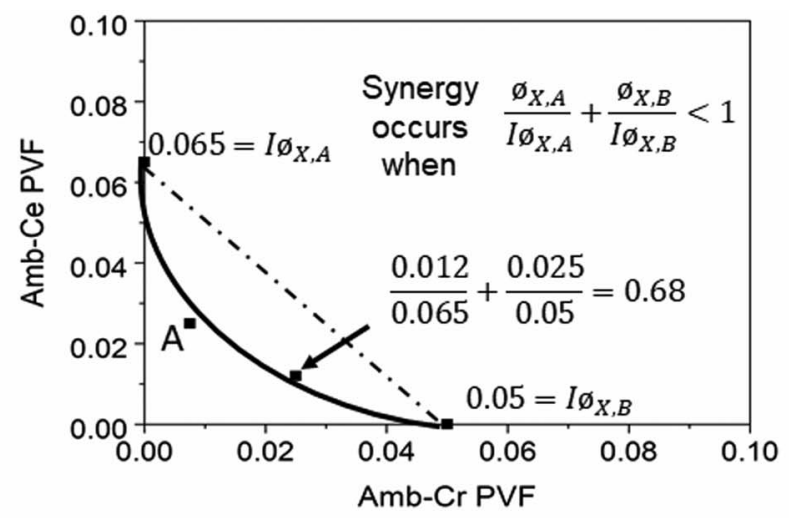

a.) $\quad v_{0} v_{i}=6.25$

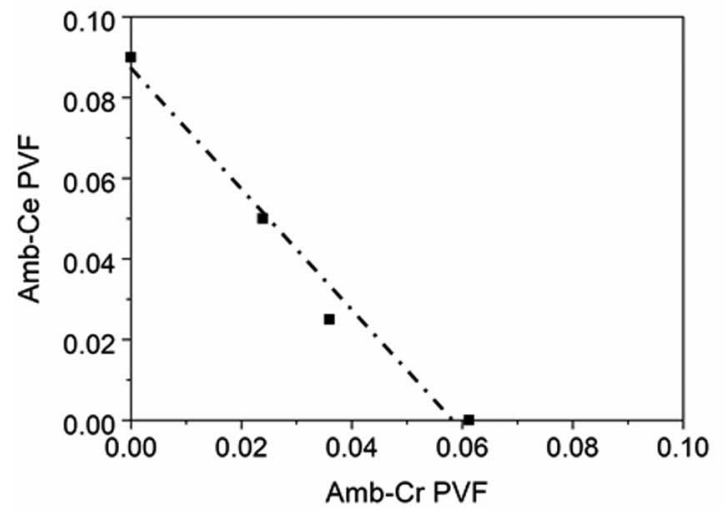

b.)

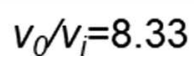

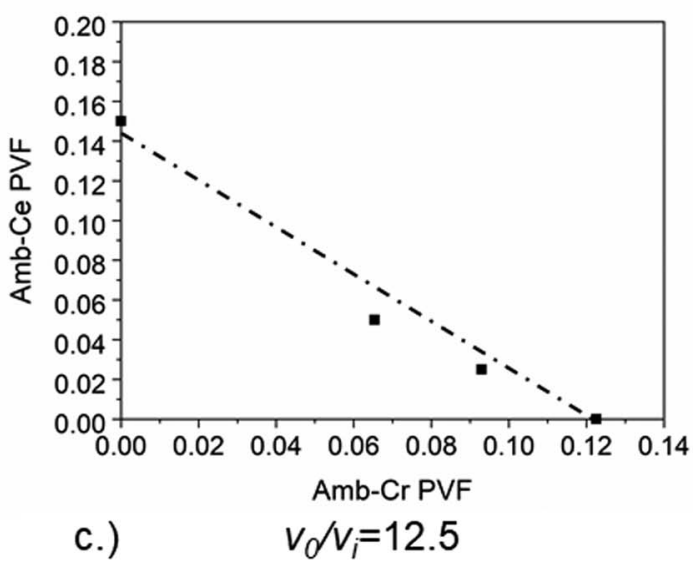

Figure 10. Isoboles showing the Amb-Ce and Amb-Cr combination pairs required to achieve a reduction in corrosion driven cathodic delamination such that a.) $v_{o} / v_{i}=6.5$ b.) $v_{o} / v_{i}=8.3$ and c.) $v_{o} / v_{i}=12.5$.

$\frac{\phi_{X, A}}{I \phi_{X, A}}+\frac{\phi_{X, B}}{I \varnothing_{X, B}}$ is referred to as the combination index) applies.

$$
\frac{\emptyset_{X, A}}{I \emptyset_{X, A}}+\frac{\emptyset_{X, B}}{I \emptyset_{X, B}}=1
$$

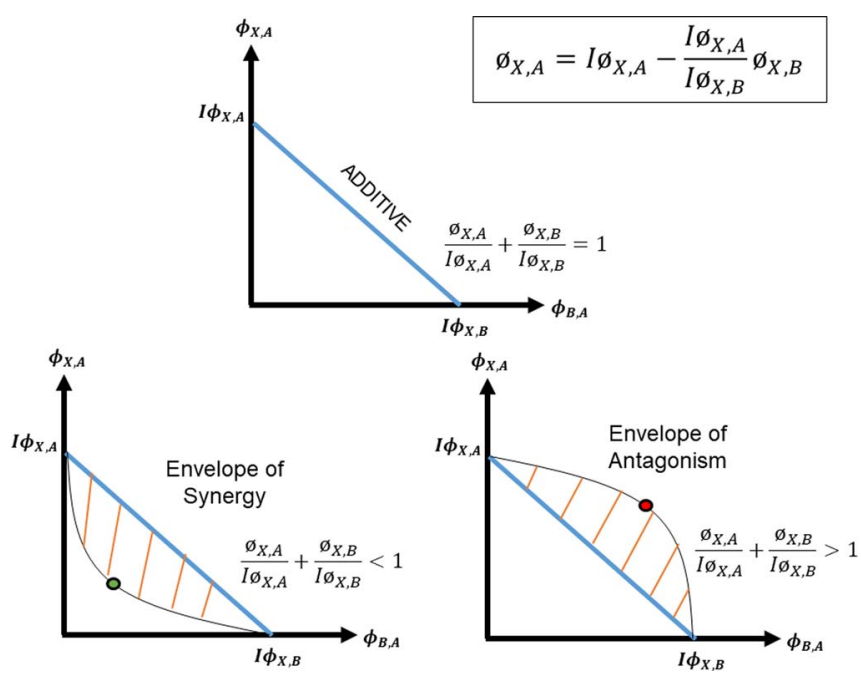

Figure 11. A schematic representation of the process used to determine whether an inhibitor pair behave synergistically.
Combination points $\left(\varnothing_{X, A}, \emptyset_{X, B}\right)$ which fall within the 'envelope' of synergy represent synergistic pairs and the combination index is less than 1 . Conversely, combination points $\left(\varnothing_{X, A}, \emptyset_{X, B}\right)$ which fall within the 'envelope' of antagonism represent antagonistic pairs and the combination index is greater than 1 .

In the case of Figure 10a $\left(v_{o} / v_{i}=6.25\right)$ combination points lie below the additive line and it can therefore be deduced that the Amb$\mathrm{Cr} / \mathrm{Amb}-\mathrm{Ce}$ combination is, to some extent, working synergistically. The synergy can be quantified by calculating the combination index (CI) using Equation 16. The value obtained for the point indicated is 0.68 . The biggest deviation from the additive line is observed at point A for which the Amb-Ce $\emptyset_{\text {pig }}$ to Amb-Cr $\emptyset_{\text {pig }}$ ratio is 3.3 and it would therefore appear as though the maximum synergistic effect occurs when the Amb-Ce $\emptyset_{\text {pig }}$ to Amb-Cr $\emptyset_{\text {pig }}$ ratio is approximately $3: 1$. This ratio is unsurprising considering the charge conservation law which means that the reduction of three $\mathrm{Ce}^{4+}$ ions is required for the oxidation of one $\mathrm{Cr}^{3+}$ ion via Equation 13. In comparison, for Figure $10 \mathrm{~b}\left(v_{o} / v_{i}=8.33\right)$ and Figure $10 \mathrm{c}\left(v_{o} / v_{i}=12.5\right)$ any synergistic effect is suppressed.

The limited synergy observed in all cases is believed to be a result of competing precipitation of ceria (Equation 10) ${ }^{30}$ which occurs at $\mathrm{pH}$ values in line with those observed in the underfilm electrolyte ${ }^{31}$ and prevents the formation of any inhibiting hexavalent oxy-anions. Regardless, the use of isobolograms is deemed a suitable way by which to quantify the synergistic effect of corrosion inhibitors and to determine regions of maximum synergy. The synergistic effect of an inhibitor pair is conventionally analyzed using data obtained for small number of inhibitor concentration combinations. In comparison, the sensitivity of the isobologram methodology allows one to draw conclusions regarding the behavior of inhibitor pairs over large concentration ranges. A good example of this is illustrated by the pair considered during this 
paper, for which synergy limited synergy is observed for cases of low inhibitor concentration and when the Amb-Ce $\emptyset_{\text {pig }}$ to Amb-Cr $\emptyset_{\text {pig }}$ ratio is approximately $3: 1$. Conversely, little synergy is observed at high $\emptyset_{\text {pig }}$, or for conditions when the Amb-Ce $\emptyset_{\text {pig }}$ to Amb-Cr $\emptyset_{\text {pig }}$ ratio varies significantly from 3:1. It is therefore a useful tool which can be utilized during investigative work into hexavalent chromium replacement technologies.

\section{Conclusions}

A systematic time lapse photography study into the inhibition of cathodic PVB coating disbondment from a HDG substrate has been completed to show that;

- Both Amb-Cr and Amb-Ce based pigments are able to reduce the rate of PVB coating disbondment when used in isolation.

- Amb-Cr and Amb-Ce based pigments are able to reduce the rate of PVB coating disbondment when used in combination.

- A methodology based on Loewe's isobolgrams can be used to characterize the interaction (in terms of synergistic, additive or antagonistic behavior) between a pair of corrosion inhibitors when used in conjunction with one another.

It is proposed that;

- In the case of Amb-Ce the $\mathrm{Ce}^{4+}$ released upon electrolyte exposure hydrolyses and forms an insoluble ceria based corrosion product which acts as a barrier to electron transfer.

- In the case of Amb-Cr a $\mathrm{Cr}(\mathrm{OH})_{3}$ corrosion product is formed.

- When used in combination the oxidizing $\mathrm{Ce}^{4+}$ released upon electrolyte exposure is reduced. This reaction is coupled to the oxidation of $\mathrm{Cr}^{3+}$, from which a transient dichromate species is formed.

- The limited synergy between Amb-Cr and Amb-Ce is a result of the competing precipitation of ceria which occurs at elevated $\mathrm{pH}$ levels and limits the oxidation of $\mathrm{Cr}^{3+}$.

Despite the limited synergy exhibited by the system described here, isobolograms have been presented as a useful tool by which to quantify the synergistic effect of two corrosion inhibitors used in combination, and to provide information regarding regions (inhibitor concentrations) at which maximum synergy is achieved. This methodology has great potential for use in the ongoing effort to discover replacements for hexavalent chromate-based inhibitor chemistries.

\section{Acknowledgments}

The authors would like to thank Tata Steel UK, Akzo Nobel, for funding this work. HDG samples were provided by Tata Steel UK.

\section{ORCID}

N. Wint (D) https://orcid.org/0000-0002-9229-5728

\section{References}

1. J. Sander, Coil Coating, Vincentz, Hanover (2014).

2. Regulation (EC) No 1907/2006 of the European Parliament and of the Council of 18 December 2006 concerning the Registration, Evaluation, Authorisa- tion and Restriction of Chemicals (REACH), establishing a European Chemicals Agency, amending Directive 1999/45/EC and repealing Council Regulation (EEC) No 793/93 and Commission Regulation (EC) No 1488/94 as well as Council Directive 76/769/EEC and Commission Directives 91/155/EEC, 93/67/EEC, 93/105/EC and 2000/21/EC. Available at: https://eur-lex.europa.eu/legal-content/ EN/TXT/PDF/?uri=CELEX:32006R1907.

3. Commission Regulation (EU) 2018/675 of 2 May 2018 amending the Appendices to Annex XVII to Regulation (EC) No 1907/2006 of the European Parliament and of the Council concerning the Registration, Evaluation, Authorisation and Restriction of Chemicals (REACH) as regards CMR substances. Available at https://eur-lex.europa. eu/legalcontent/EN/TXT/?qid=1532946798646\&uri=CELEX:32018R0675.

4. O. Gharbi, S. Thomas, C. Smith, and N. Birbilis, Materials Degradation, 2, 12 (2018).

5. P. Tianlan and M. Ruilin, Journal of Rare Earths, 27, 159 (2009).

6. M. Kendig, M. Cunningham, and Evans R, ECS Transactions, 24, 27 (2010).

7. M. Kendig and D. J. Mills, Progress in Organic Coatings, 102, 53 (2017).

8. M. W. Kendig, Chromate-generating corrosion inhibitor, US Pat. 7691498 B2, issued April 62010.

9. J. Vander Kloet, W. Schmidt, A. W. Hassel, and M. Stratmann, Electrochimica Acta, 48, 1211 (2003).

10. G. Williams and H. N. McMurray, Journal of the Electrochemical Society, 148, B377 (2001).

11. M. W. Kendig and R. G. Buchheit, Corrosion, 39, 379 (2003).

12. V. I. Pokhmurskii, I. M. Zin, L. M. Bilyi, and A. V. Vasylyk, Materials Science, 36, 878 (2000).

13. H. N. McMurray, D. Williams, G. Williams, and D. Worsley, Corrosion Engineering Science and Technology, 38, 112 (2003).

14. M. Zin, V. I. Pokhmurskii, J. D. Scantlebury, and S. B. Lyon, Journal of the Electrochemical Society, 148, B293 (2001).

15. K. Aramaki and N. Hackerman, Journal of the Electrochemical Society, 116, 568 (1969).

16. S. A. S. Dias, S. V. Lamaka, T. C. Diamantino, and M. G. S. Ferreira, Journal of the Electrochemical Society, 161, C215 (2014).

17. D. Snihirova, S. V. Lamaka, P. Taheri, J. M. C. Mol, and M. F. Montemor, Surface and Coatings Technology, 303, 342 (2016).

18. T. H. Muster, H. Sullivan, D. Lau, D. L. J. Alexander, N. Sherman, S. J. Garcia, T. G. Harvey, T. A. Markley, A. E. Hughes, P. A. Corrigan, A. M. Glenn, P. A. White, S. G. Hardin, J. Mardel, and J. M. C. Mol, Electrochimica Acta, 67, 95 (2012).

19. S. Loewe and Die Mischiarnei, Klin Wochenschr, 6, 1077 (1927)

20. S. Loewe, Die quantitativen probleme der pharmakologie, Ergebn Physiol, 27, 47 (1928).

21. S. Loewe, "The problem synergism and antagonism of combined drugs," Arzneimittelforschung, 3, 285 (1953).

22. S. Loewe, "Antagonisms and antagonists," Pharmacological Reviews, 9, 237 (1957).

23. L. Zhao, J. L.-S. Au, and M. Guillaume Wientjes, Frontiers in Bioscience, (Elite edition), 2, 241 (2010).

24. C. A. J. Richards, H. N. McMurray, and G. Williams, Corrosion Science, 154, 101 (2019).

25. P. C. Dodds, G. Williams, and J. Radcliffe, Progress in Organic Coatings, 102, 107 (2017).

26. J. C. de Andrade, J. C. Rocha, and N. Baccan, Analyst, 109, 645 (1984).

27. M. Stratmann, H. Streckel, and A. Leng, Corrosion Science, 32, 467 (1991).

28. A. Leng, H. Streckel, and M. Stratmann, Corrosion Science, 41, 547 (1998).

29. M. Cappadonia, K. Doblhofer, and D. Woermann, Journal of Colloid and Interface Science, 143, 222 (1991).

30. H. N. McMurray, G. Williams, and D. A. Worsley, Journal of The Electrochemical Society, 149, B154 (2002).

31. W Fürbeth and M Stratmann, Corrosion Science, 43, 207 (2001)

32. G. Williams and H. N. McMurray, Underfilm/coating corrosion, in: B. R. A. Cottis, M. Graham, R. Lindsay, S. Lyon, T. J. A. Richardson, D. J. D. Scantlebury, and H. Stott, (Eds.), Shreir's Corrosion, Elsevier Science, 2009, pp. 988.

33. E. Koehler, Corrosion, 33, 209 (1977).

34. K. N. Allahar, K. Ogle, and M. E. Orazem, ECS Proceedings. 2002-24, 474

35. A. Leng, H. Streckel, and M. Stratmann, Corrosion Science, 41, 579 (1999).

36. H. Leidheiser and W. Wang, Journal of Coatings Technology, 53, 77 (1981)

37. J. D. B. Sharman, J. M. Sykes, and T. Handyside, Corrosion Science, 35, 1375 (1993).

38. M. Pourbaix, Atlas of Electrochemical Equilibria in Aqueous Solutions, Pergamon Press (1966).

39. N. N. Greenwood and A. Earnshaw, Chemistry of the Elements, Pergamon Press (1984). 